\title{
Hurricanes and the Harvesting Decisions ${ }^{1}$
}

\author{
Fritz Roka, Robert Rouse, Steve Futch, and Ron Muraro ${ }^{2}$
}

Within a six-week period during 2004, Florida was struck by an unprecedented onslaught of three hurricanes. Between August (Friday) 13th and September 26th, Charley, Frances, and Jeanne tore through major areas of the Florida citrus production region. For any grove in the path of these hurricanes, a portion of the crop was blown off or damaged. Since these storms struck before fruit reached maturity, none of the fruit blown to the ground was usable for either the fresh or processed markets. Even fruit remaining on trees that were managed for the fresh market may have been damaged by wind scarring to a point where its peel quality was unsuitable for the fresh market.

For growers facing significant fruit losses, they confront an important decision on whether to harvest the remaining portion of the crop. Complicating a citrus grower's decision is the strong likelihood that harvesting costs will increase above "normal" production years.

This paper addresses the generic question of whether a crop should be harvested after sustaining significant loss. This paper provides a citrus grower with a roadmap to determine the economic criteria for harvesting the remaining crop. Conversely, when is it in the best economic interest for a grower to abandon the remaining crop? While the hurricanes of 2004 motivated this paper, the analysis is applicable to any situation arising from natural disasters, pest infestations, or collapsing market prices.

The question of whether to harvest or to abandon a crop can be summarized by the following decision rule: harvest, no matter how low the yield, as long as the total harvest costs and associated taxes are less than the delivered-in value of the fruit at the processing plant or the packinghouse. The "Go" or "No-Go" harvest decision rests on determining an economic threshold.

The economic threshold for harvesting includes only those costs associated with harvesting or post-harvesting activities. Equally important are costs that should NOT be included, such as fertilizer, chemicals, insurance premiums, electrical bills, and other production-related costs which have already been paid at the time of harvest. An economic threshold depends only on the costs that accrue during and following harvest.

1. This document is FE624, a publication of the Food and Resource Economics Department, Florida Cooperataive Extension Service, Institute of Food and Agricultural Sciences, University of Florida, Gainesville, FL. Published March 2006. Please visit the EDIS website at http://edis.ifas.ufl.edu.

2. Fritz Roka, Associate Professor, Food and Resource Economics Department, and Bob Rouse, Associate Professor, Horticultural Sciences Department, Southwest Florida Research and Education Center, Immokalee, FL; Steve Futch, Extension Agent IV, Horticultural Sciences Department, and Ron Muraro, Professor, Food and Resource Economics Department, Citrus Research and Education Center, Lake Alfred, Florida; Florida Cooperative Extension Service, Institute of Food and Agricultural Sciences, University of Florida, Gainesville, FL. 


\section{Processed Fruit}

The economic threshold for harvesting processed citrus is based on the delivered-in price; the costs to pick, roadside, and haul; and any taxes required by government agencies. If a grower is a member of an industry association where annual fees are based on production, then those membership fees need to be included in the economic threshold as well.

To make the calculation simple and straightforward, all prices and costs should be expressed in terms of dollars per box. Harvest rates, hauling costs, and taxes usually are quoted on a per-box basis. Delivered-in prices for processed citrus, however, usually are expressed as dollars per pound-solids. With an estimate of the pound-solids per box, a grower can convert the delivered-in price from pound-solids to price per box.

Haul costs are not affected by crop yield, but rather by the distance between a grove and a processing plant. The haul price increases as the distance between grove and plant increases.

Government agencies such as the Florida Department of Citrus, the Florida Department of Agriculture and Consumer Services, and the U.S. Department of Agriculture assess grower taxes and inspection fees on a per-box basis. Taxes and fees are set prior to the start of the harvest season. Furthermore, some grower associations set their annual membership fees on the basis of grove production. Consequently, a grower's total tax or membership fee depends on the quantity of fruit that is sold through a processing plant or packinghouse.

At the crux of the harvest decision are the pick and roadside costs. These are costs, quoted in terms of dollars per box, to remove fruit from the tree (pick) and deliver the fruit to the bulk trailers at the edge of the grove (roadside). In many cases, pick and roadside rates fluctuate with harvesting conditions. Hand-harvest crews typically negotiate for higher piece rates when grove yields are low or when harvesting conditions are tougher than normal. The economic threshold for harvesting becomes the maximum amount a grower is willing to pay to pick and roadside the available fruit on the tree. The threshold is determined by subtracting the haul charge and all required taxes from the delivered-in price. Table 1 illustrates an example in which the delivered-in price for processed fruit is $\$ 3.50$ per box. If the haul charge is 50 cents and grower taxes/fees are 20 cents per box, then the grower should be willing to pay up to $\$ 2.80$ per box to pick and roadside the remaining fruit. If a harvesting contractor quotes pick and roadside costs more than $\$ 2.80$, the grower will lose money on the harvesting operation and may choose to abandon the remaining crop. On the other hand, if the quoted pick and roadside costs are less than $\$ 2.80$, the grower should proceed forward and harvest the remaining crop. Assuming that crop yield, fruit size, and tree conditions have been factored into the quoted pick and roadside rate, it does not matter whether there are 50 or 500 boxes per acre to be picked.

Sometimes there is uncertainty in market prices and/or harvest costs. In addition, cull rates at a processing plant may increase due to the inclusion of damaged fruit. A grower can compensate for this uncertainty by lowering the economic threshold level. Referring to the example above, a grower can lower the economic threshold to $\$ 2.50$ per box to cover any risk from paying more for harvesting than the final value of the fruit. The reduction amount is arbitrary and depends solely on a grower's knowledge and concern of likely risks.

To summarize for processed fruit, a grower needs to gather the following information:

1. Contract or expected delivered-in price. (Price will likely be in terms of pound-solids. Therefore, use average pound-solids per box to convert to a per box price.)

2. Haul rates.

3. Taxes and fees charged by government agencies (Florida Department of Citrus, Florida Department of Agriculture and Consumer Services, and U.S. Department of Agriculture) and from grower associations on whose annual assessments are based on production.

4. Harvester's contract price to pick and roadside fruit. The quoted rate must reflect the harvesting conditions and expectations of the harvesting crew. 
Cost, grove, and fruit conditions may vary by block. Therefore it is important for the above information to be as accurate as possible and specific for a given set of grove conditions.

\section{Fresh Citrus}

The decision criterion for harvesting fresh citrus is the same as for processed citrus. Fresh citrus, however, has four additional factors to consider. First, a grower needs to know (or at least have an educated guess) of delivered-in prices for both fresh and processed fruit. Second, a grower needs an estimate of the expected pack-out percentage. Only that fruit which is packed for the fresh market will receive fresh market prices. It is important to carefully consider how wind scarring and other hurricane-induced effects may affect pack-out rates. Fruit that does not meet fresh market standards will be "eliminated" and sold to the processing plant. Third, for all fruit that is packed for the fresh market, the grower will be assessed a "packing" charge. Fourth, a grower must include the elimination charge and a second haul charge that covers the costs of transporting eliminations from the packinghouse to a processing plant.

The far right-hand columns of Table 1 illustrate an example relevant to a fresh fruit grower. The delivered-in price for packed fresh citrus is $\$ 10.00$ per field box ( $\$ 5$ per carton). Eliminations are valued the same as for processed fruit, $\$ 3.50$ per box delivered to the processing plant. Pack-out is expected to be $35 \%$ and the packing cost is $\$ 0.60$ per packed box. The initial haul cost from the grove to the packing house is 50 cents. A grower is assessed 60 cents a box for eliminations and the second haul for eliminations to the processing plant is 40 cents. Taxes and fees for fresh fruit add another 35 cents per box. The economic harvest threshold is the "blended" delivered-in price of $\$ 5.78(\$ 10.00 * 35 \%+\$ 3.50 *$ $65 \%$ ) less $\$ 1.71$, or $\$ 4.07$ per box. So long as a harvesting contractor quotes a pick and roadside rate of less than \$4.07, the grower should harvest the crop. Again, it is a "GO" decision to harvest whether the block picks 50 or 500 boxes to the acre. Note that as pack-out rates or delivered-in prices increase, the economic threshold for harvesting increases as well.
To summarize, a fresh fruit grower must know, or at least have an educated guess about:

1. Contract or expected delivered-in prices for both fresh and processed markets. As with the processed market, a grower should utilize average pound-solids per box to convert a pound-solids price to a per box price.

2. Haul rates.

3. Packinghouse charges: packing costs, elimination charges, and hauling costs from the packinghouse to the processing plant.

4. Taxes and fees charged by government agencies (Florida Department of Citrus, Florida Department of Agriculture and Consumer Services, and U.S. Department of Agriculture) and from grower associations on whose annual assessments are based on production.

5. Harvester's contract price to pick and roadside fruit, which reflects the harvesting conditions of the specific block.

\section{Hidden Costs}

So far, this article has focused solely on economic values related to the current year's crop. Horticultural aspects also must be considered in the salvage harvesting decision. The most important horticultural question is: what will be the effect on next year's production if a portion of this year's crop is not harvested? Ramirez and Krezdorn (1977) found that holding crops of 'Hamlin' and 'Valencia' oranges until late in the season depressed yields the following year, both on the basis of boxes of fruit and pound-solids per tree. Ramirez and Krezdorn (1975) found that 'Marsh' grapefruit yields were reduced the following year in direct relation to the lateness of harvest the previous year. Trees that were spot-picked partially overcame the exhaustive effects of late harvesting. Juice quality, however, was unaffected by the previous year's harvest date. In California, it was found that large yields depressed tree growth during the current season and yield the following year. Advancing the harvest date reduced the depressing effect on the ensuing crop (Hodgson, et al., 1941). Jones and Cree (1954), in a 12-year 
experiment with 22-year old 'Valencia', found late September harvest at Riverside, compared with an early June harvest, decreased yields in all years by a mean of 31 percent. Hilgeman et al. (1993) in Arizona found similar results with 'Valencia' oranges.

\section{Concluding Comments}

When a significant portion of a crop is lost due to a hurricane or other adverse events, a grower faces a psychologically difficult salvage operation. Carry-over inventories, consumer demand, and production responses from other regions (i.e., Brazil) will determine whether fruit prices increase in response to reduced Florida citrus supply. Even if fruit prices increase, a significant loss of production will likely bring financial losses on the affected growers.

It is important for growers not to focus on the magnitude of fruit losses, but instead to focus on making the correct decision on how to handle the remaining crop. So long as the actual costs of harvesting, hauling, packinghouse charges, taxes and other required fees are less than a predetermined harvest cost threshold, growers will reduce their total loss by recovering the remaining boxes of fruit. More importantly, abandoning the remaining current crop may have adverse production implications in succeeding years.

\section{References}

Hilgeman, R.H., J.A. Dunlap, and F.O Sharp. 1993. Effect of time of harvest on Valencia oranges in Arizona on fruit grade and size and yield the following year. Journal of the American Society for Horticultural Science 90:103-109.

Hodgson, R.W., S.H. Cameron, and E.R. Egger. 1941. Effect of time and amount of harvesting on alternate bearing and fruit size in Valencia orange. Proceedings of the American Society for

Horticultural Science 38:196-202.

Jones, W.W. and C.B. Cree. 1954. Effect of time of harvest on yield, size, and grade of 'Valencia' oranges. Proceedings of the American Society for Horticultural Science 64:139-145.
Ramirez, J.M. and A.L. Krezdorn. 1975. Effect of date of harvest and spot picking on yield and quality of grapefruit. Proceedings of the Florida State Horticultural Society 88:40-44.

Ramirez, J.M. and A.L. Krezdorn. 1977. Influence of date of harvest on yields of 'Hamlin' and 'Valencia' oranges and 'Marsh' grapefruit. Proceedings of the Florida State Horticultural Society 88:40-44. 
Table 1. Determining the economic threshold for harvesting citrus in either the processed or fresh markets.

\begin{tabular}{|c|c|c|c|c|}
\hline \multirow[b]{2}{*}{ Delivered-in Price } & \multirow[b]{2}{*}{$\$ / b x$} & \multirow{2}{*}{$\begin{array}{c}\text { Harvest for Processed Market } \\
\$ 3.50\end{array}$} & \multicolumn{2}{|c|}{ Harvest for Fresh Market } \\
\hline & & & $\$ 10.00$ & $\$ 5.78^{1}$ \\
\hline Pack-out (fresh only) & $\%$ & - & $35 \%$ & \\
\hline Haul Charge & $\$ / b x$ & $\$ 0.50$ & $\$ 0.50 * 100 \%$ & $\$ 0.50$ \\
\hline Elimination Charge & $\$ / b x$ & - & $\$ 0.60 * 65 \%$ & $\$ 0.39$ \\
\hline Elimination Haul & $\$ / b x$ & - & $\$ 0.40 * 65 \%$ & $\$ 0.26$ \\
\hline Packing Charge & $\$ / b x$ & - & $\$ 0.60 * 35 \%$ & $\$ 0.21$ \\
\hline Taxes and Other Fees & $\$ / b x$ & $\$ 0.20$ & $\$ 0.35 * 100 \%$ & $\$ 0.35$ \\
\hline Economic Threshold & $\$ / b x$ & $\$ 2.80$ & & $\$ 4.07$ \\
\hline
\end{tabular}

